Canadian Journal of Higher Education Revue canadienne d'enseignement supérieur

Volume 47, No. 1, 2017, pages 49 - 60

\title{
Government-Sponsored Bursaries: Examining Financial Support for Residents to Study at Home
}

Melissa James-MacEachern

University of Prince Edward Island

\begin{abstract}
This study examines the George Coles bursary program-a financial aid plan designed to "keep residents at home" so they can attend university, by providing a bursary in their first year of university following high school graduation. The study offers insight into higher education students' financial circumstances, thereby suggesting policy direction for governments and higher education institutions wishing to retain talent and support student financing. The findings show that the resident students considered in the study appeared to value the bursary. However, none of the key metrics related to participation in or conversion to the home institution indicated that the bursary impacted enrolment or participation. This research highlights the importance of utilizing financial aid in combination with other policies to help students access higher education.
\end{abstract}

\section{Résumé}

Cette étude examine le programme boursier George-Coles, un programme d'aide financière conçu pour " garder les étudiants chez eux » afin qu'ils puissent fréquenter l'université de leur région. Le programme remet une bourse durant la première année universitaire, après l'obtention d'un diplôme d'études secondaires. La présente étude a permis de mieux comprendre les questions d'ordre financier des étudiants inscrits à l'enseignement supérieur, et ce qui peut aider à orienter les politiques des gouvernements et des établissements d'enseignement supérieur relativement à la rétention des 
talents et au soutien financier des étudiants. L'étude révèle que les étudiants locaux semblaient apprécier la bourse, mais aucun des paramètres clés liés à la participation ou à la conversion à l'établissement d'origine n'indique que la bourse a eu un effet sur le taux d'inscription universitaire des régions. Cette étude met en évidence l'importance d'utiliser l'aide financière, en combinaison avec d'autres politiques, dans le but d'aider les étudiants à accéder à l'enseignement supérieur.

\section{Introduction}

Governments have a vested interest in increasing accessibility to higher education in order to improve social and economic outcomes in society. "In most countries, especially developed ones, higher education generates a significant part of a country's stock of skilled labor" (Viaene \& Zilcha, 2013, p. 78). For many governments, higher education is a key economic development tool that can assist in growing skills and innovation in a jurisdiction. It has been said that higher education confers numerous benefits both to the individual and to society, including higher earnings, lower rates of unemployment and government dependency, an increased tax base, and greater civic engagement (Marope, Wells, \& Hazelkorn, 2013). As higher education is a public good, governments also have an interest in managing funding to higher education institutions to ensure affordability and accessibility for its citizens.

The aim of this paper is to explore the impact of a government-sponsored bursary program in a provincial jurisdiction, Prince Edward Island (PEI), Canada. This paper explores the perception of the George Coles bursary program ("the bursary") by resident students attending the home university institution and examines the impacts on participation and conversion following the implementation of the bursary at that institution. PEI has only one university-the University of Prince Edward Island (UPEI)-and, as such, it provides an interesting case study on university access. The George Coles bursary program was created by PEI's provincial government to "keep residents at home" by providing a financial incentive of $\$ 2,000$ in 2008 , which was subsequently increased to $\$ 2,200$ in 2012, for first-year resident undergraduate students who attend the home institution. A secondary goal was to increase accessibility to higher education through a reduction in first-year tuition for direct-entry high school students. The program has not been evaluated since its inception.

The purpose of this paper is to

- examine the home institution's eligible (resident) students' perceptions and awareness of the George Coles bursary,

- assess changes in participation, enrolment, and student loans to the home institution since the bursary was instituted, and

- propose options related to the bursary for policy makers and administrators in order to improve resident retention and accessibility.

This study is important as it can assist in identifying methods to improve resident participation while supporting institutions to be sustainable. It can also help policy makers and senior administrators evaluate options regarding the appropriation of funding to both institutions and students that address the priorities of both government and institutions. 


\section{Background}

The University of Prince Edward Island ("the home institution") is the only university in the province of PEI (population 146,283; Statistics Canada, 2015). Economic development is a challenge for Canada's smallest province, as it competes with many other larger, more diversified economies and labour markets to attract and retain a talented workforce. In less than 45 years, PEI's median age gradually increased from 24.8 to 43.3 (Prince Edward Island Statistics Bureau, 2014). Although PEI's recent economic growth rate is $0.5 \%$, interprovincial out-migration of its population has continued to be a problem. Net interprovincial migration has been negative nine times in the last 10 years (Prince Edward Island Statistics Bureau, 2014). Youth out-migration, for both work and education, has continued to challenge the province's economy and has become a focus for policy makers.

The provincial government seeks to mitigate this out-migration of youth and human capital through the development of policy initiatives related to higher education. The introduction of the George Coles bursary is one such program aimed at young residents to retain them in their home province during their higher education studies. The policy imperative for the bursary has three main components. Firstly, the program acknowledges the benefits students on Prince Edward Island can derive from obtaining diplomas, certificates, or degrees. The bursary program attempts to encourage resident students to pursue postsecondary education, allowing them to obtain the educational benefits provided. Secondly, the bursary puts forth a financial investment towards resident students in order to ensure they are financially capable of entering postsecondary school. Finally, the bursary program supports the continued sustainability of publicly funded postsecondary educational institutions on PEI through encouraging resident students to remain there when pursuing further education (Student Financial Services, 2015).

Implemented in 2008, the George Coles bursary program offers PEI students financial aid as they pursue postsecondary education in their home province. Upon completing 24 consecutive weeks when enrolled as a full-time PEI student at a degree-, diploma-, or certificate-granting institution, students are eligible to obtain a one-time bursary of up to $\$ 2,200$. Resident students must be registered at one of the four PEI postsecondary schools, those being UPEI, Holland College, Maritime Christian College, or Collège Acadie Î.-P.-É. Students must be residents of PEI attending a postsecondary institution full time for the first time.

For PEI students who meet the George Coles bursary qualifications, there is no application process to follow in order to receive the financial award. Rather, the bursary is conditionally credited to each eligible student's account at their respective postsecondary institution in January of their first year. Then, the bursary amount is typically released to each student in February after completion of 24 consecutive weeks of education. An important distinction of the George Coles bursary payment is that the provincial government's Student Financial Services directs funds to the postsecondary institution rather than to eligible students.

Since the inception of the bursary, the number of recipients who met the eligibility requirements has varied from 2008 to 2015 at UPEI. In the first year of the program, 595 first-year students at UPEI received the award, which was valued at a total of $\$ 1,190,000$. In the next academic year, 2009-2010, there was a 13\% decrease in eligible UPEI students 
for the award, as only 518 students received the financial support provided by the bursary, for a value of $\$ 1,036,000$. There was another decrease in recipients from the 2009-2010 school year to the 2010-2011 school year of $3 \%$, as only 500 students obtained the bursary, which required $\$ 1,000,000$ in funding. There was a further decline in the 2011-2012 academic year of $5 \%$ to 476 students and $\$ 952,000$ required to provide these awards. The recipients continue to decrease in the 2012-2013 school year, with 450 students and a total value of $\$ 990,000-$ another $5 \%$ decrease, but a $4 \%$ increase in the monetary funds required. The number of first-year students obtaining the award at UPEI continued to decline in the 2013-2014 school year, by $9 \%$, with 409 students receiving a total of $\$ 899,800$.

\section{Financial Aid: Retention and Accessibility}

An accessible higher education system is barrier free and permits people from all backgrounds to study on a reasonably equal basis (Usher \& Medlow, 2010). Much of the research on accessibility focuses on participation, which is one measure for gauging accessibility. Participation can be viewed as a metric to ensure there is an educated and knowledgeable labour force available to meet current and future labour market needs.

Various efforts have been made in jurisdictions to support resident participation in higher education, including those directed at "keeping students at home" for various reasons, such as retaining talent, enhancing labour market performance, and reaping the economic benefits of tuition and spending by students. In Canada, four provinces have implemented resident scholarship and bursary programs for those who choose to study in their home provinces: Prince Edward Island, Nova Scotia, Ontario, and Saskatchewan.

Other such programs in the United States have been based on retaining talent and residents. Several of these programs have been documented in the literature, including the "Bright Futures scholarship program" that was implemented in the state of Florida. A study conducted by Zhang et al. (2013) on the program found "significant enrollment effects at Florida's public 4- and 2-year institutions, for both full-time and part-time enrollment. This large growth is at least in part due to reduced out-migration of Florida's resident students attending out-of-state institutions" (p. 746).

In a similar study of 21 US state-sponsored scholarship programs implemented between 1980 and 2009, designed to reduce the "brain drain" and keep residents attending higher education in their home states, Hawley and Rork (2013) determined that

these plans increase the in-state enrollment rate, but have no positive impact on the subsequent number of graduates. While aggregate migration trends remain unaffected as a result of these plans, we find the out-migration rate of young college educated individuals decreases 3 to 5 years after the adoption of a plan. (p. 242)

These scholarships, bursaries, or tuition rebate programs have been popular amongst politicians and voters, as they offer discounts or incentives to residents for attending "home" institutions. Typically, these programs have been viewed as providing greater accessibility and ensuring the retention of a talented and educated labour force. As discussed, higher education has been a significant economic development tool and is deemed to be instrumental in providing a talented and educated workforce in countries and regions. Others have criticized these programs as an "income transfer from the poorest of residents to the 
richest (based on lottery demographics)" (Hawley \& Rork, 2013, p. 243). Regardless of financial or merit-based needs, these grants are provided to each and every student who participates at a "home" or state institution. Critics of these programs believe that the universal application of government grants (which are taxpayer financed) to such programs gives greater financial benefits to a wealthier cohort who are already more likely to attend higher education institutions.

These studies indicate a positive relationship between resident participation and accessibility in higher education through the use of financial incentives. Discourse around the globe and in Canada has focused on the rising costs of higher education and the perception of these financial barriers to higher education. Research indicates access to higher education remains a challenge for many families. The disparity in university attendance is evident in developed countries such as Canada. In 2010, approximately $82 \%$ of students from high-income families attended college, in comparison to only $52 \%$ of students from low-income families (University of Saskatchewan, 2011). Similar disparities exist in the United Kingdom, where it is found that gaps between "students coming from advantaged and disadvantaged backgrounds are large and that much of the socio-economic gap in HE participation rates is driven by particularly low participation rates for students at the bottom of the income distribution" (Valbuena, 2012). In the United States, recent statistics indicate that $64 \%$ of the lowest quartile of household incomes continue on to higher education, compared with $86 \%$ of the highest quartile (U.S. Census Bureau, 2012). While participation has increased in many of these jurisdictions, accessibility gaps remain for certain cohorts of students.

There is a generally accepted belief that government policies around tuition fees and providing student financial aid can increase access to postsecondary education. However, some studies have found that the demand for postsecondary education is relatively price inelastic (Finnie, Childs, \& Qiu, 2012). This means that even with increases in tuition or decreases in average income, students are still choosing to attend higher education institutions (Vaccaro, 2012). And while some studies indicate positive correlations between financial aid and resident retention, not all financial support has been found to influence accessibility or improve retention. There is research that indicates financial aid impacts specific cohorts of students differently. In the study "Awareness, Take-up and Impact of Institutional Bursaries and Scholarships in England" (Callender, 2009), it was found that the importance of bursaries varied by "individual, attitudes, perceptions and characteristics [and that] ... bursaries had the largest impact on the HE decisions of students who were anxious about the costs of going to university" (p. 15). The study further suggested that student perceptions of the cost of university were a larger determinant of the importance of the bursary than family income.

Finnie et al. (2012) and Vaccaro (2012) reinforced these findings regarding the perception of affordability and access. Their research explored accessibility and the perception of financial barriers to university and found that there is likely an issue amongst prospective students of the perceived value of university education (Finnie et al., 2012). With comments such as postsecondary education "costs too much," both of these studies implied that for some students, the benefits of higher education (such as a higher-paying job in the future) do not, in their minds, outweigh the costs of receiving that education (Vaccaro, 2012). This implication suggests that perceptions create barriers to higher edu- 
cation, and lack of knowledge about the true costs and benefits of attending university impacts accessibility, as does a lack of understanding about the financial aid system (Finnie et al., 2012).

These studies indicate that financial assumptions amongst prospective students are important determinants in both the perception of accessibility and the perceived value of the investment in university education, and not all students are impacted in the same manner by financial aid.

\section{Methodology}

For the purposes of this study, only data related to the home university institution are used, and all comparison data, i.e., participation, student loans, etc., are based on university data versus all other types of postsecondary or higher education institutions.

The home institution (UPEI) primarily focuses on undergraduate programs in the liberal arts domain. Over the past 10 years, undergraduate enrolment to the institution has increased by $1.9 \%$. However, enrolment has been relatively stagnant in recent years, which have seen a declining domestic youth population, resulting in a decrease from 3,722 undergraduate students in 2011 to 3,588 in 2013 (University of Prince Edward Island, 2014). The institution has been steadily increasing the number of international students to fill the void. Over the past five years, the institution has grown international enrolments at five times the rate of its regional counterparts, mainly due to a more aggressive recruitment effort that has increased international students by $259 \%$ in comparison to $118 \%$ throughout the region (Maritime Provinces Higher Education Commission, 2014). With the decline of PEI's youth population and the relatively stagnant undergraduate growth in Canada, the institution must seek to maintain and increase its enrolment in order to manage fiscal sustainability.

To achieve the research objectives, several data sources were examined. A review of the findings from the "Survey of First Year Students at the University of Prince Edward Island" (MacEachern \& Yun, 2015) was used to explore student perceptions of financial matters, in particular the George Coles bursary. The survey questionnaire explored a number of decision-making influences, and for the purposes of this paper, the data from the "financial" questions were used to determine

- students' awareness of the George Coles bursary,

- the influence of the bursary on affordability and accessibility, and

- the influence of the bursary on attending UPEI specifically.

This survey was designed specifically for first-year students at UPEI and sought respondents' views on a variety of issues relating to socio-demographics, marketing, financial matters, evaluation, and expectations regarding their experiences at UPEI. The survey was pursued on an ongoing basis, but data collected during the period from September 3 to October 8, 2014, were used for this report. During the survey period, a total of 901 respondents participated (81.4\% participation rate of 1,107 eligible first-year students), and 616 respondents completed the survey (55.6\% response rate of all eligible students and $68.4 \%$ use rate of all collected surveys), indicating a very high response rate for the survey. In terms of statistical accuracy, a sample of this size has a sampling error of $\pm 2.63 \%$ at a $95 \%$ confidence level. 
Secondly, data from the provincial government's Student Financial Services were utilized to determine student loans for first-year students attending UPEI since the inception of the bursary program. Thirdly, the institution's participation rate data and conversion data over the same period were analyzed to determine trends since the inception of the bursary program.

\section{Findings}

The George Coles bursary has become widely known amongst resident students attending the home institution since the program was established in 2008. Student feedback indicates that there is a strong value attached to the bursary for those who attend the home institution. An examination of the key metrics yields interesting findings regarding the use of bursaries and financial supports. With $83.4 \%$ of respondents indicating they were aware of the bursary, there is a very high awareness level of the program. Respondents also indicated the bursary influenced their decision to attend the home institution (79.3\%), suggesting it affected their choice of institution and the decision to study in their home province. In addition, $66.8 \%$ of respondents indicated the bursary made it affordable to attend university. These findings indicate the bursary is influencing students' decision making and their attitudes and perceptions towards university, university accessibility, and choice of institution. More importantly, these findings suggest that the bursary is achieving its policy objectives related to resident students pursuing university at home by supporting the notion of affordability.

To determine the impact of the bursary on student debt, student loan data were examined over a 10-year period. Since the inception of the bursary in 2008, the rate of student loans for first-year, direct-entry high school students to the home institution has declined with the exception of 2012, when a modest increase was experienced. The rate of student loans for direct-entry students (students attending the home institution directly from high school) was $46.2 \%$ in 2008 but dropped to $32.4 \%$ in 2014, which is a significant decline in student loan recipients over this period.

While there are other factors that may impact the level of student loan recipients, the bursary appears to influence the rate of student loans received by first-year, direct-entry PEI students. As indicated in the survey, students believe that their university is more affordable due to the bursary. This measure suggests that the bursary may impact students' need for or eligibility within the provincial student loan system. However, other reasons that may account for this decline in student loan participation have been identified, including: aversion to debt; greater financing options from other financial institutions; self-sourced income; or access to other financial resources such as scholarships or other government-supported programs (Collins, 2010).

Data were also reviewed from the accounting office at the home institution with respect to students who received the bursary. Since 2008, after receiving the bursary, only $4 \%$ of students subsequently withdrew any funds from their student account. Students can only withdraw funds from their account if all tuition and fee commitments to the institution are met. This indicates that the majority of students appear to be utilizing the bursary for tuition and fee costs related to the home institution.

Canada has one of the highest university participation rates in the world, at $25.6 \%$. PEI's participation, at $32.4 \%$, has been above the national average for over a decade (Mari- 
time Provinces Higher Education Commission, 2014). A review of participation data illustrates PEI resident participation in university (ages 18-24) ranged from $30.9 \%$ in 2003 to $32.4 \%$ in 2012. At the same time, participation in the home institution by residents in the same cohort was $21.7 \%$ in 2003 but declined to $20.7 \%$ in 2013 (http://www.mphec.ca/ media/71910/Participation_Rate_Update.pdf). These data indicate that participation for residents has remained high for well over a decade, with residents increasing their participation at universities across the country. For UPEI, participation has been relatively constant for residents, indicating that market share appears to be declining for the home institution even with the introduction of the bursary.

Further data were explored relating to conversion to the home institution (resident applicants who enrol and begin their studies as direct-entry high school students). This metric decreased from almost 30\% in 2008 to approximately $27 \%$ in 2014. Again, these findings reinforce the loss in market share related to participation. The introduction of the George Coles bursary does not appear to be improving the conversion of resident students to the home institution. Students may be choosing other post-secondary options inside or outside PEI, or they may not be attending any postsecondary institution. However, it does not appear that the bursary program itself has attracted a greater proportion of resident, direct-entry high school graduates to attend the home institution.

The study by Callender (2014) found that bursaries do impact decisions for approximately 30\% of students, but these are "price-sensitive" students, who are worried about financial matters but may not experience true accessibility barriers to university. It is interesting to note that conversion rates to UPEI did not improve with the introduction of the George Coles bursary, while at the same time, the awareness and value of the bursary were quite high. The findings of the Callender study offer a suggestion regarding the resident students' perceived value of the George Coles bursary while market share to the institution declined. It appears that resident students may also be highly sensitive to the costs of higher education and seek affordable education at home. This may account for the lack of improvement in conversion to and participation in the home institution, as these students historically have been attending the home institution due to factors such as affordability.

The bursary appears to influence residents' perceptions and decision making related to attending the home institution, according to their survey responses. However, it does not appear to improve participation amongst the resident population. The participation rate to the home institution has not increased, and since 2003, it has even declined, while conversion rates have witnessed a marginal decline since the bursary was introduced.

\section{Discussion and Conclusion}

The George Coles bursary program has significant value and awareness amongst residents attending the home university and appears to reinforce a perception amongst resident students that the bursary has enabled them to affordably attend university. However, other research has indicated that the broad-based application of bursaries appears to have little impact on overall participation. Given these findings, several approaches could be undertaken to improve upon the George Coles bursary program and financial supports to prospective students. The perception of affordability is an issue for specific cohorts of students, as indicated in the literature on the impact of resident financial aid, but these issues do not appear to be related to income-based factors. Therefore, continued 
reinforcement of the costs and benefits of a university education at the home institution would be warranted to ensure that residents clearly understand the value of university.

PEI as a whole has a high participation rate for university enrolment. As enrolments in high school within the province are projected to decline by almost $24 \%$ in the K-12 system over the next five years (Department of Education and Early Childhood Development, 2014), the participation rates will need to increase to almost $40 \%$ to maintain current enrolment levels. Policy issues arise regarding the George Coles bursary, including whether it can help improve resident participation at the home institution and whether it provides the best use of funds for enhancing accessibility to higher education. Ultimately, after seven years of residents expecting and valuing the bursary, it becomes a difficult political decision to change the policy. Students indicate they value the bursary and perceive it as influencing their decision to attend the home institution. Eliminating the bursary may have perceived impacts on the affordability and attractiveness of the institution. However, it may not impact actual participation. The policy implications related to the bursary should be viewed beyond simple participation or conversion to the home institution--for example, reducing student debt and improving general perceptions of accessibility.

A review of the conversion rates for a 10-year period demonstrates a consistent percentage of direct-entry students from provincial high schools going to the home institution. While students indicate the bursary is inducing them to stay at home, the figures do not support this. There is no evidence to suggest what the conversion rate would be without the bursary; hence, it may be suggested that the conversion rate would be substantially lower than the current rate, but to what degree is unclear. In an increasingly competitive market, conversion rates could have dropped without the bursary; it may be helping to maintain conversion to a certain extent. Regardless, evidence suggests residents are increasingly participating in university while the home institution is losing market share. This loss of market share is an area of concern and should addressed by both the institution and the provincial government.

The rate of student loans for first-year students to the home institution has declined every year since the inception of the bursary, with the exception of 2012. The research does not indicate why student loans have declined over this period; however, it may be due to the introduction of the bursary. As incomes rise, students may not qualify, based on income testing, or they may be receiving other financial income through employment or other means. The study highlights the need to examine the student loan program and student financial need within PEI. It is difficult to discern from the data the factors impacting student loan rates. The declining rate of student loans amongst first-year home institution students warrants a review to determine the reason for this decline. If the bursary is creating an environment of declining financial need, then the costs and benefits of the bursary should be weighed against other policy objectives for university-related funding.

The review of the literature indicates that secondary school academic performance, socioeconomic background, and other social factors influence participation and accessibility to higher education. According to Deller and Oldford's 2011 study, titled "Participation of Low-Income Students in Ontario," low-income students over-estimate the cost of higher education. However, wealthier families are more likely to go to university compared to poorer ones (Berger, Motte, \& Parkin, 2009), so participation tends to be lower for lower-income students. Financial concerns are one significant barrier to higher 
education and are a consideration in determining the institution of choice, along with other factors such as program availability, and influences such as rankings, parents, and friends. The bursary represents one instrument to help students attend the home institution. However, other policy and financial incentives for targeted groups could be instituted to encourage participation. The culture of "higher education" begins early in one's social and educational development. Early intervention with parents, students, and other influencers throughout a student's development is instrumental in fostering the aspiration and desire to pursue higher education.

A review of both the policy imperative and the intended outcomes related to the George Coles bursary should be undertaken. The program appears to be broadly understood by stakeholders and is influential in student decision making and perception of affordability. However, if the program is designed to support the sustainability of the home institution while enhancing access to higher education for residents, then the program may not be deemed successful based on key metrics of conversion and participation.

The bursary does not address participation for students who do not directly enter higher education from high school. The policy consideration regarding retaining human capital and talent should be assessed against the potential impact the bursary may have on those who are not direct-entry high school students. This may be an instrumental policy lever that can positively impact overall participation in the home province while developing human capital and retaining an educated workforce for PEI.

\section{Study Limitations}

This study identified accessibility issues for higher education that are of importance when considering declining youth populations, future labour market demands, and the need to sustain higher education institutions. This is undoubtedly a challenging period, given the changing social and demographic forces within PEI and across Canada. A comprehensive examination of the policies and programs to address these forces needs to be undertaken. This study was limited to exploring the George Coles bursary from the perspective of resident students at the home institution. Students who did not attend the home institution were not surveyed. As a result, the awareness and influence (or lack thereof) of the bursary are not known for other cohorts who either chose other institutions or did not choose to enter higher education.

It is recommended that further study be undertaken to examine students who chose other paths following high school, and the impact of the perception of affordability on choice. In particular, further studies into accessibility and student decision making early in the academic career of students would be worthwhile. This research on high school student decision making and parental influence should be undertaken in order to develop more comprehensive interventions and programs to support government and institutional goals.

The goal of the bursary is to provide financial assistance to resident students who attend the home institution. The policy objectives indicate a need to attract and retain human capital. With a growing international student population and declining local market share for the home institution, further study into retaining and growing human capital, both domestic and international, would be beneficial.

Further research into accessibility to university for specific cohorts of students is warranted. As the research indicated, not all students have the same perceptions and atti- 
tudes towards university, including its costs and benefits. Understanding the differences amongst cohorts would be helpful for strategically developing and enhancing financial aid and supports for specific targeted groups.

This study will be useful for boosting higher education enrolment, assisting institutions in improving recruitment and retention activities, and helping governments to adopt policies that address specific needs for learning and skills. The study has contributed to the understanding of financial aid for students in Canada, in particular the use of government investment to retain talent in a jurisdiction. The findings will be useful to researchers and policy makers as they explore accessibility to and participation in university, and the goals of achieving human capital growth in jurisdictions.

\section{References}

Berger, J., Motte A., Parkin, A. (Eds.). (2009). The price of knowledge: Access and student finance in Canada (4th ed.). Montréal, QC: The Canada Millennium Scholarship Foundation.

Callender, C., \& National Institution for Social Research. (2009). Awareness, take-up and impact of institutional bursaries and scholarships in England. Bristol, UK: Office for Fair Access.

Collins, S. (2010). Focus groups on federal and provincial student loan uptake. Toronto, ON: Ekos Research.

Deller, F., \& Oldford, S. (2011). Participation of low-income students in Ontario. Toronto, ON: Higher Education Quality Council of Ontario.

Department of Education and Early Childhood Development. (2014). Enrolment statistics, 2014. Charlottetown, PEI: The Government of Prince Edward Island.

Finnie, R., Childs, S., \& Qiu, H. (2012). Patterns of persistence in postsecondary education: New evidence for Ontario. Toronto, ON: Higher Education Quality Council of Ontario.

Hawley, Z., \& Rork, J. (March 2013). The case of state funded higher education scholarship plans and interstate brain drain. Regional Science and Urban Economics, 43(2), 242-249.

MacEachern, M., \& Yun, D. (2015). Survey of first year students. Charlottetown, PEI: University of Prince Edward Island.

Maritime Provinces Higher Education Commission. (2014). Trends in maritime education. Participation rate update (2003-2013). Fredericton, NB: Author.

Marope, P. T. M., Wells, P. J., \& Hazelkorn, K. (Eds.). (2013). Rankings and accountability in higher education: Uses and misuses. Paris, France: UNESCO.

Prince Edward Island Statistics Bureau. (2014, February). Prince Edward Island population projections 2014-2052. Charlottetown, PEI: Department of Finance and Municipal Affairs.

Statistics Canada. (2015, September). Population estimates and projections. Retrieved from http://www.statcan.gc.ca/tables-tableaux/sum-som/lo1/csto1/demoo2a-eng.htm. 
Student Financial Services. (2015). George Coles bursary. Charlottetown, PEI: Province of Prince Edward Island.

University of Prince Edward Island. (2014). Enrolment management plan. Charlottetown, PEI: Author.

University of Saskatchewan. (n.d.). Institutional planning and assessment. Retrieved from http://www.usask.ca/ipa/assessment/surveys/accessibility and affordability.php

U.S. Census Bureau. (2012). United States Census Bureau statistics. Retrieved from https://www.census.gov/library/publications/2011/compendia/statab/131ed.html

Usher, A., \& Medow, J. (2010). Global higher education rankings 2010: Affordability andaccessibility in comparativeperspective. Retrieved from http://www.iregobservatory. org/pdf/HESA_Global_Higher_EducationRankings2010.pdf.

Vaccaro, A. (2012). An analysis of access barriers to post-secondary education. Retrieved from http://www.collegequarterly.ca/2012-vol15-numo4-fall/vaccaro.html

Valbuena, J. (2012). A longitudinal perspective on higher education participation in the UK. Discussion paper [Abstract]. University of Kent School of Economics.

Viaene, J.-M., \& Zilcha, I. (2013). Public funding of higher education. Journal of Public Economics, 108(C), 78-89.

Zhang, L., Hu, S., \& Sensenig, V. (2013). The effect of Florida's Bright Futures Program on college enrollment and degree production: An aggregated-level analysis. Research in Higher Education, 54(7), 746-764.

\section{Contact Information}

Melissa James-MacEachern

University of Prince Edward Island

School of Business

mjames@upei.ca

Melissa James-MacEachern is an assistant professor at the University of Prince Edward Island's School of Business. Currently working on her $\mathrm{PhD}$ in higher education research, evaluation and enhancement at the University of Lancaster, Melissa is interested in higher education research and policy. Formerly the Deputy Minister of Innovation and Advanced Learning and Tourism and Culture with the Prince Edward Island Provincial Government, she was responsible for initiatives to support PEI's long-term economic growth, particularly in the areas of higher education, immigration, and skills and labour market development. 